\title{
Produção contínua de ácido láctico por Lactobacillus curvatus a partir de melaço de cana-de-açúcar suplementado
}

\section{Utilization of supplemented sugarcane molasses for continuous production of lactic acid by Lactobacillus curvatus}

\author{
Andréa Rocha de Oliveira ${ }^{1}$, João Batista Buzato ${ }^{2}$, Maria Célia de Oliveira Hauly ${ }^{2 *}$
}

\begin{abstract}
Resumo
Melaço é uma matéria prima de baixo custo e rico em nutrientes para a fermentação láctica. $\mathrm{O}$ ácido láctico tem aplicação na indústria farmacêutica, cosmética, têxtil, de couro, química e de alimentos, onde são utilizados cerca de $82 \%$ de sua produção mundial. Neste trabalho foi avaliada a produção de ácido láctico por Lactobacillus curvatus em fermentação contínua de melaço de cana-de-açúcar, previamente tratado com invertase e suplementado com extrato de levedura e peptona. Os valores de taxa de diluição $\mathrm{D}=0,05 ; 0,10 \mathrm{e} 0,15 \mathrm{~h}^{-1}$ foram testados à temperatura de $37^{\circ} \mathrm{C}$. As amostras foram coletadas na fase estacionária de crescimento, para medidas de $\mathrm{pH}$, determinação de açúcares redutores, biomassa, produção de ácido láctico e viabilidade celular. Nestas condições, o consumo de açucares redutores diminuiu de 7,1; $6,4 \mathrm{e}$ 4,8g/L com o aumento respectivo da taxa de diluição. A maior produção de ácido láctico $(13,8 \mathrm{~g} / \mathrm{L})$ foi obtida na taxa de diluição de $0,05 \mathrm{~h}^{-1}$, enquanto que $\mathrm{D}=0,10 \mathrm{e} 0,15 \mathrm{~h}^{-1}$ suportaram a produção de 10,2 e $7,1 \mathrm{~g} / \mathrm{L}$, respectivamente. Os valores mais altos de biomassa $(1,98 \mathrm{~g} / \mathrm{L})$ e viabilidade celular $\left(2,03 \times 10^{\circ} \mathrm{UFC} / \mathrm{mL}\right)$ também foram alcançados na menor taxa de diluição $\left(\mathrm{D}=0,05 \mathrm{~h}^{-1}\right)$. A produção de ácido láctico, por $L$. curvatus em melaço, previamente tratado com invertase e suplementado, foi mais adequada na menor taxa de diluição.

Palavras-chave: Lactobacillus curvatus, melaço de cana-de-açúcar, suplementação, fermentação contínua, ácido láctico
\end{abstract}

\begin{abstract}
Several by-products and raw-materials of food and agricultural industries have been used as culture medium. It is rich nutrients sources, and it is considered low cost and high availability of molasses as a substrate can be used in lactic fermentation. Lactic acid has tradicionally been obtained by chemical process, however, lactic acid production by fermentative process is considered most viable economically. Lactic acid has application in different industries such as pharmaceutical, cosmetic, textiles, leather, chemical and food industries, where about $82 \%$ of all world production is used. In this work, lactic acid production by L. curvatus under continuous culture on sugarcane molasses supplemented with yeast extract and peptone was evaluated. Dilution rates tested were 0,$05 ; 0,10$ and $0,15 \mathrm{~h}^{-1}$ at $37^{\circ} \mathrm{C}$. Samples were taken for $\mathrm{pH}$, reducing sugar, lactic acid, biomass and cellular viability measurements under steady state conditions. When the $\mathrm{D}$ was 0,$05 ; 0,10$ and $0,15 \mathrm{~h}^{-1}$, the reducing sugar consumption was 7,$1 ; 6,4$ and $4,8 \mathrm{~g} / \mathrm{L}$, respectively. Highest lactic acid production $(13,8 \mathrm{~g} / \mathrm{L})$ was obtained when $\mathrm{D}=0,05 \mathrm{~h}^{-1}$ was used, while at $\mathrm{D}=0,10$ and $0,15 \mathrm{~h}^{-1}$, lactic acid production reached 10,2 and $7,1 \mathrm{~g} / \mathrm{L}$, respectively. The highest values of biomass $(1,98 \mathrm{~g} / \mathrm{L})$ and cell viability $\left(2,03 \times 10^{9} \mathrm{CFU} / \mathrm{mL}\right)$ were reached at the lowest dilution rate tested $\left(0,05 \mathrm{~h}^{-1}\right)$. In conclusion, the results showed that under tested conditions, low values of dilution rate were most suitable for continuous lactic acid production by L. curvatus in supplemented sugarcane molasses.
\end{abstract}

Key words: Lactobacillus curvatus, sugarcane molasses, supplementation, continuous fermentation, lactic acid

1 Mestre em Ciência e Tecnologia de Alimentos / TAM-UEL

2 Docentes do Depto. de Bioquímica e Biotecnologia/UEL Cx. Postal 6001, CEP 86051-970, PR. E-mail: mcoh@ uel.br Telefone: 3371-4270 Celular: Fax : 3371- 4611 -( secretaria geral do CCE).

* Autor para correspondência 


\section{Introdução}

O ácido láctico é um ácido orgânico de alto valor comercial, devido às suas aplicações. Cerca de $82 \%$ da produção mundial é utilizada pela indústria de alimentos, sendo o restante utilizado nas indústrias farmacêutica, cosmética, têxtil, de couro e química (DEMIRCI et al.,1998; EVANGELISTA; NIKOLOV, 1996). O ácido láctico pode ser obtido por síntese química ou bioconversão através da fermentação láctica (CHOUDHURY ; BASHA; SWAMINATHAN, 1998), sendo esta mais viável economicamente.

A fermentação láctica pode utilizar diversos glicídeos ou matérias-primas ricas em glicose, sacarose ou lactose. A escolha do carboidrato a ser bioconvertido depende da linhagem selecionada, visto que as cepas diferem quanto ao metabolismo relativo a diferentes fontes de carbono (ROYCHOUDHURY; SRIVASTAVA; SAHAI.,1995). Oliveira (1995) verificou que na fermentação láctica utilizando $L$. curvatus a sacarose não foi a fonte de carbono mais adequada. Desta maneira, substratos ricos em sacarose necessitam de tratamento prévio (ácido ou enzimático) em função da baixa atividade de invertase desse microrganismo.

Diversos produtos e subprodutos da indústria de alimentos e da agroindústria, por serem baratos e abundantes, têm sido empregados como substrato para a produção de substâncias comercialmente importantes como ácidos orgânicos, acetona, etanol e outros (MORAES; CAPALBO; MORAES, 1991). Resíduos e matérias-primas agroindustriais que contém alto teor de carboidratos podem ser utilizados na fermentação láctica, sendo que o soro de leite e melaço são os de maior interesse econômico.

Cerca de 18 milhões de toneladas de melaço de cana-de-açúcar são produzidos por ano no Brasil pelo setor sucroalcooleiro. Por seu baixo custo, alta disponibilidade e alto teor de açúcares fermentáveis, esta matéria-prima vem sendo empregada como substrato para diferentes tipos de fermentação. Para se obter um maior rendimento, tanto da produção de biomassa quanto da produção de ácido láctico, vários pesquisadores têm suplementado o meio de cultivo com fontes de nitrogênio (DEMERCI et al., 1998; PAYOT; CHEMALY; FICK, 1999; AMRANE; PRIGENT, 1998; SELMER-OLSEN; SORHAUG,1998) .

O objetivo deste trabalho foi produzir ácido láctico através de fermentação contínua por L. curvatus a partir de melaço de cana-de-açúcar, previamente tratado com invertase e suplementado com extrato de levedura $2 \%(\mathrm{~m} / \mathrm{v})$ e peptona $4 \%(\mathrm{~m} / \mathrm{v})$, na concentração de $10 \%(\mathrm{~m} / \mathrm{v})$.

\section{Material e Métodos}

\section{Melaço de cana-de-açúcar}

Foi utilizado melaço de cana-de-açúcar safra 99/ 00 procedente da Usina de Açúcar e Álcool da COROL (Cooperativa Agropecuária Rolândia Ltda.) localizada na região Norte do Paraná. A matériaprima continha, em média, $70 \%$ de açúcares totais, sendo $54 \%$ de sacarose e $16 \%$ de açúcares redutores.

\section{Microrganismo}

Foi utilizado Lactobacillus curvatus isolado de silagem de milho por Oliveira (1995), mantido em ágar MRS , ágar MRS inclinado contendo proteose peptona, extrato de carne, extrato de levedura, glicose, complexo monooleato e sorbitol, citrato de amônio, acetato sódico, sulfato de magnésio, sulfato de manganês, fosfato disódico e ágar. $\mathrm{O}$ pH inicial foi 6,5. Após autoclavado, o meio foi mantido sob refrigeração a $4^{\circ} \mathrm{C}(\mathrm{MAN}$; ROGOSA; SHARPE, 1960).

\section{Meio para fermentação}

O melaço de cana-de-açúcar diluído a 10\% (m/v) em água destilada,foi tratado com $2 \%(\mathrm{v} / \mathrm{v})$ de invertase $(14,09 \mathrm{U} / \mathrm{mL})$ a $37^{\circ} \mathrm{C}$ durante 20 minutos a pH 4,7. Após incubação, a reação foi inibida em água fervente por 5 minutos e o meio foi suplementado com extrato de 
levedura (Biobrás) na concentração de $2 \%(\mathrm{~m} / \mathrm{v})$ e peptona (Biobrás) a $4 \%(\mathrm{~m} / \mathrm{v})$ e o $\mathrm{pH}$ ajustado para 6,2 .

\section{Processo fermentativo}

L. curvatus mantido sob refrigeração foi ativado, três vezes antes de ser utilizado no processo fermentativo ,através de repiques sucessivos a cada 24 horas, após cultivado a $37^{\circ} \mathrm{C}$ em leite em pó desengordurado e na concentração de $10 \%(\mathrm{~m} / \mathrm{v})$. A seguir, foi transferido para o meio de fermentação e mantido a $37^{\circ} \mathrm{C}$ durante 24 horas. Em seguida, uma alíquota de $10 \%(\mathrm{v} / \mathrm{v})$ foi transferida para um fermentador cilíndrico de $0,5 \mathrm{~L}$, com controle automático de temperatura de $37^{\circ} \mathrm{C}$ e agitação de $150 \mathrm{rpm}$, contendo $0,3 \mathrm{~L}$ de meio de fermentação. Após 3 horas, para o cultivo atingir a fase logarítmica, foi ligada a bomba peristáltica, iniciandose a fermentação contínua. Durante o processo fermentativo, foram testadas as taxas de diluição de 0,05; 0,10 e 0,15h $\mathrm{h}^{-1}$. Em cada taxa de diluição avaliada , aguardou-se até que o cultivo atingisse a fase estacionária de crescimento, verificado por valores de biomassa, açúcares redutores e ácido láctico constantes. A partir daí, as amostras foram coletadas, no decorrer da $5^{\mathrm{a}}$ a $10^{\mathrm{a}}$ geração do microrganismo.

\section{Análise do processo fermentativo}

O processo fermentativo foi analisado quanto aos parâmetros de rendimento do ácido láctico $(\mathrm{g} / \mathrm{g})$, produtividade (g/L.h) e consumo de açúcar (\%) conforme ( KWON; KAUL; MATTIASSON, 1996).

O rendimento foi calculado pela relação da concentração de ácido láctico pela concentração de açúcar consumido ; a produtividade pela relação da concentração de ácido láctico pelo tempo de fermentação e o consumo de açúcar fazendo-se a relação da diferença ( ARTi - ARTf) pela (ARTi x 100) onde $\mathrm{ARTi}=$ açúcar redutor total inicial e ARTf $=$ açúcar redutor total final.

\section{Determinações analíticas}

a) Determinação de biomassa

Amostras do caldo fermentado foram centrifugadas a 2000xg por 10 minutos, reservando-se o sobrenadante para as outras análises. O precipitado foi lavado duas vezes com solução salina estéril e centrifugado. A biomassa foi determinada pela medida da densidade óptica da suspensão celular em 600nm e convertida em peso seco $(\mathrm{g} / \mathrm{L})$ usando uma curva de calibração de densidade óptica versus biomassa seca (KWON; KAUL; MATTIASSON, 1996).

b) Determinação da viabilidade celular

A viabilidade celular foi determinada por semeadura em profundidade de diluições apropriadas da amostra em ágar MRS (ZAYED; WINTER, 1995) com incubação a $37^{\circ} \mathrm{C}$ por 48 horas.

c) Determinação de $\mathrm{pH}$

$\mathrm{O} \mathrm{pH}$ foi monitorado utilizando-se um potenciômetro digital da marca Hanna modelo HI 9321.

d) Determinação de ácido láctico

O ácido láctico foi extraído do caldo fermentado de acordo com o método descrito por Silva (1981). Foi utilizada uma coluna Aminex HPX $-87 \mathrm{H}$ (300mm x $7.8 \mathrm{~mm} \varnothing)$, específica para análise de ácidos orgânicos e pré-coluna contendo a mesma resina de exclusão iônica. A fase móvel constituiuse de $\mathrm{H}_{2} \mathrm{SO}_{4} 5 \times 10^{-3} \mathrm{~mol} \mathrm{~L}^{-1}$ mantida sob fluxo de

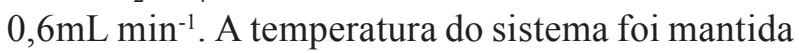
a $35^{\circ} \mathrm{C}$ e a pressão foi de $52 \mathrm{mmHg}$. Para injeção no cromatógrafo, o extrato obtido de acordo com Silva (1981) foi filtrado em membrana milipore $0,45 \mu \mathrm{m}$. O volume de injeção foi de $20 \mu \mathrm{L}$. Foi utilizado $210 \mathrm{~nm}$ para o detector UV - VIS. O padrão interno constituiu-se de uma mistura de ácido oxálico, acético, cítrico, málico, succínico e fórmico. Padrões de ácido láctico nas concentrações de $2,08 \times 10^{-2} \mathrm{~mol} \mathrm{~L}^{-1} ; 4,7 \times 10^{-2} \mathrm{~mol} \mathrm{~L}$ ${ }^{1}$ e $6,25 \times 10^{-2} \mathrm{~mol} \mathrm{~L}^{-1}$ foram utilizados na curva de referência para cálculo da concentração das amostras (ZHENG et al., 1996). 
e) Determinação de açúcares redutores

Os açúcares redutores foram determinados pelo método de Somogyi (1945) e Nelson (1944). Para determinação de açúcares redutores totais, realizouse hidrólise ácida prévia das amostras, seguida de neutralização e finalmente determinação dos açúcares redutores totais pelo método de Somogyi (1945) e Nelson (1944).

\section{Análise Estatística}

Os resultados foram analisados pela comparação entre as médias, através do teste de Tukey (GOMEZ, 1985).

\section{Resultados e Discussão}

O melaço de cana-de-açúcar "in natura" diluído a $10 \%(\mathrm{~m} / \mathrm{v})$ apresentou $10,4 \mathrm{~g} / \mathrm{L}$ de açúcares redutores e após tratamento com $2 \%(\mathrm{v} / \mathrm{v})$ de invertase $(14,09 \mathrm{U} /$ $\mathrm{mL})$, o teor de açúcares redutores do melaço de canade-açúcar $10 \%(\mathrm{~m} / \mathrm{v})$ aumentou para $34,0 \mathrm{~g} / \mathrm{L}$. O tratamento com invertase elevou em $226,9 \%$ os açúcares redutores no meio de fermentação. MartinezGonzález et al. (1988) trataram melaço de cana-deaçúcar com ácido sulfúrico 10 e $20 \%$ sob temperatura de $60^{\circ} \mathrm{C}$ e obtiveram 91,2 e $98 \%$ de conversão, respectivamente. Apesar da hidrólise ácida fornecer índices de conversão elevados e ser utilizada industrialmente, a hidrólise enzimática ainda é mais vantajosa e indicada em processos fermentativos por não gerar compostos indesejáveis (COUTINHO FILHO; HORI, RIBEIRO, 1999). Os processos biotecnológicos como a sacarificação do amido ou a hidrólise da sacarose são mais rentáveis com a ajuda de enzimas microbianas, uma vez que estas reagem com seus substratos de forma livre ou imobilizadas em suportes sólidos (JAGNOW; DAWID, 1991), o que pode facilitar no processo industrial e evitar o aparecimento de produtos indesejáveis.

A produção de ácido láctico, biomassa e consumo de açúcar redutor pelo L. curvatus na fermentação contínua, utilizando-se como meio de cultivo melaço de cana-de-açúcar tratado com invertase, contendo $70,8 \mathrm{~g} / \mathrm{L}$ de açúcar redutor total, e suplementado com extrato de levedura $2 \%(\mathrm{~m} / \mathrm{v})$ e peptona $4 \%(\mathrm{~m} / \mathrm{v})$ são apresentados na Tabela 1.

Tabela 1. Produção de ácido láctico, biomassa e consumo de açúcar redutor pelo Lactobacillus curvatus na fermentação contínua de melaço de cana-de-açúcar tratado com invertase e suplementado com extrato de levedura $2 \%(\mathrm{~m} / \mathrm{v})$ e peptona $4 \%(\mathrm{~m} / \mathrm{v})$.

\begin{tabular}{|c|c|c|c|}
\hline \multirow[t]{2}{*}{ Parâmetros analisados } & \multicolumn{3}{|c|}{ taxas de diluição $\left(\mathrm{h}^{-1}\right)$} \\
\hline & 0,05 & 0,10 & \\
\hline $\mathrm{pH}$ final & 4,04 & 4,21 & 4,30 \\
\hline $\mathrm{AR}_{\mathrm{r}}(\mathrm{g} / \mathrm{L})$ & 26,9 & 27,6 & 29,2 \\
\hline $\operatorname{ART}_{\mathrm{r}}(\mathrm{g} / \mathrm{L})$ & 31,0 & 38,0 & 46,8 \\
\hline Ácido láctico $(\mathrm{g} / \mathrm{L})$ & 13,8 & 10,2 & 7,10 \\
\hline Biomassa (g/L) & 1,98 & 1,74 & 1,69 \\
\hline
\end{tabular}

Na tabela 1, o teor inicial de açúcar redutor foi de 34,0g/L na fermentação contínua de melaço de canade-açúcar $10 \%$ (m/v) suplementado. O consumo de açúcares redutores nas diferentes taxas de diluição foi de 7,$1 ; 6,4$ e $4,8 \mathrm{~g} / \mathrm{L}$ em $\mathrm{D}=0,05 ; 0,10$ e $0,15 \mathrm{~h}^{-1}$, respectivamente, indicando que o consumo de açúcar diminui com o aumento da taxa de diluição. A quantidade de açúcar redutor residual $\left(\mathrm{AR}_{\mathrm{r}}\right)$ foi de 26,9; 27,6 e 29,2g/L nas taxas de diluição de 0,05; 0,10 e $0,15 h^{-1}$, respectivamente, sugerindo que a taxa de diluição menor é a mais adequada para o melhor aproveitamento dos açúcares do meio de cultivo.

A produção de ácido láctico foi de 13,8; 10,2 e $7,10 \mathrm{~g} / \mathrm{L}$ nas taxas de diluição de 0,$05 ; 0,10$ e $0,15 \mathrm{~h}^{-1}$, respectivamente. O teste de Tukey (GOMEZ, 1985) utilizado para comparação das médias mostrou que os resultados são significativamente diferentes ao nível de 5\%. Comparando a produção de ácido láctico, verifica-se que menores valores de $\mathrm{D}$ favorecem a produção de ácido láctico por L. curvatus. Barcena et al. (1998) também demonstraram que baixas taxas de diluição favorecem a produção de ácido láctico por L. casei. 
A produção de ácido láctico, biomassa e $\mathrm{ART}_{\mathrm{r}}$ em diferentes taxas de diluição é demonstrada na figura 1.

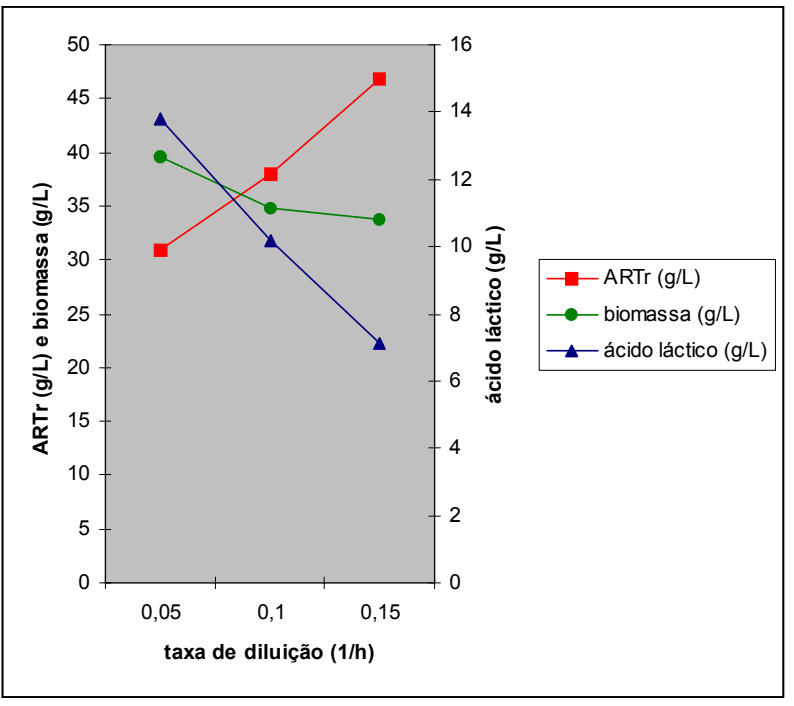

Figura 1. Efeito da taxa de diluição (D) sobre a produção de ácido láctico, produção de biomassa e açúcar redutor total residual (ARTr) na fermentação contínua de Lactobacillus curvatus em melaço de cana-de-açúcar suplementado.

A taxa de diluição deve ser considerada na produção de ácido láctico, entretanto a composição do meio de cultivo também é muito relevante. Oliveira et al.(2000) obtiveram $4,7 \mathrm{~g} / \mathrm{L}$ de ácido láctico em $\mathrm{D}=0,10 \mathrm{~h}^{-1}$ para o L. curvatus cultivado em condições similares, porém utilizando melaço de cana-deaçúcar, tratado com invertase, mas sem suplementação. No presente trabalho, utilizando-se melaço de cana-de-açúcar, tratado com invertase e suplementado com peptona $4 \%(\mathrm{~m} / \mathrm{v})$ e extrato de levedura $2 \%(\mathrm{~m} / \mathrm{v})$, a produção atingiu valor de 10,2 g/ L na taxa de diluição de $0,10 \mathrm{~h}^{-1}$, ou seja, um valor maior que o dobro na produção de ácido láctico, mostrando claramente a vantagem da suplementação do melaço. Montelongo, Chassy e McCord (1993) suplementaram melaço de soja $2 \%(\mathrm{~m} / \mathrm{v})$ com extrato de levedura $0,5 \%(\mathrm{~m} / \mathrm{v})$ para produção de ácido láctico por processo descontínuo com L. salivarus e obtiveram 5,5g/L de ácido láctico em 10 horas de cultivo, enquanto que em melaço de soja sem suplementação foram obtidos 4,2 g/L em 36 horas de cultivo.
Oliveira et al.(2000), através de fermentação contínua do L. curvatus em melaço de cana-deaçúcar sem suplementação, obtiveram valores de biomassa mais baixos $(1,10$ e $1,10 \mathrm{~g} / \mathrm{L})$, respectivamente para as taxas de diluição de $0,10 \mathrm{e}$ $0,15 \mathrm{~h}^{-1}$, que os obtidos neste trabalho ( 1,74 e 1,69g/ L), sugerindo que a suplementação do melaço favoreceu o crescimento do L. curvatus.

A viabilidade celular do L. curvatus foi de $2,03 \times 10^{9} ; 1,20 \times 10^{9}$ e $9,7 \times 10^{8} \mathrm{UFC} / \mathrm{mL}$, nas taxas de 0,$05 ; 0,10$ e $0,15 h^{-1}$, respectivamente, indicando que a viabilidade celular diminuiu com o aumento de taxa de diluição. Apesar de haver diminuição, pode-se afirmar que a viabilidade celular ainda foi alta, nas diferentes taxas de diluição e não foi afetada pelo baixo $\mathrm{pH}$ final da fermentação no meio de melaço suplementado. Cultivos preliminares do L.curvatus em meio de melaço diluído a $10 \%(\mathrm{~m} / \mathrm{v})$ sem suplementação, com extrato de levedura e peptona, apresentaram valores de viabilidade celular de $2,0 \times 10^{3} \mathrm{UFC} / \mathrm{mL}$, indicando a necessidade de suplementação do meio de cultivo para melhorar o crescimento celular.

Montelongo, Chassy e McCord (1993) demonstraram baixo crescimento de Lactobacillus quando cultivado em melaço de soja, subproduto obtido na preparação de proteína de soja o qual contém $\alpha$-galactosídeo, sem suplementação. Entretanto, estudando fermentação láctica em melaço de soja suplementado com extrato de levedura, verificaram maior crescimento celular e melhor desempenho do processo fermentativo.

Kotzamanidis, Roukas e Skaracis (2002) estudando fermentação láctica em frascos agitados, verificaram que a substituição de extrato de levedura por outras fontes de proteinas de menor custo, não melhorou a produção de ácido láctico por L. delbrueckii NCIMB 8130 cultivado em melaço de beterraba . A utilização de melaço de beterraba também foi avaliada por Bulut, Elibol e Ozer (2004) que afirmaram que a pasteurização do melaço melhora a produção de ácido láctico. 
Os resultados referentes aos parâmetros cinéticos de rendimento do ácido láctico, produtividade e consumo de açúcar redutor total obtidos na fermentação láctica contínua do L. curvatus em três diferentes taxas de diluição são apresentados na tabela 2 .

Na tabela 2, o açúcar consumido (em \%) durante o processo fermentativo foi de 56,2; 46,3 e 33,9, fornecendo rendimentos $(\mathrm{g} / \mathrm{g})$ de 0,$35 ; 0,31$ e 0,30 para as taxas de diluição de 0,$05 ; 0,10$ e $0,15 h^{-1}$, respectivamente. Portanto, o melhor rendimento $(0,35 \mathrm{~g} / \mathrm{g})$ foi obtido na menor taxa de diluição testada.

Tabela 2- Parâmetros cinéticos avaliados na fermentação contínua do Lactobacillus curvatus em melaço de canade-açúcar a $10 \%(\mathrm{~m} / \mathrm{v})$, previamente tratado com invertase e suplementado com $2 \%(\mathrm{~m} / \mathrm{v})$ de extrato de levedura e $4 \%$ $(\mathrm{m} / \mathrm{v})$ de peptona.

\begin{tabular}{lccc}
\hline \multirow{2}{*}{ Parâmetros cinéticos } & \multicolumn{3}{c}{ Taxas de diluição $\left(\mathrm{h}^{-1}\right)$} \\
\cline { 2 - 4 } & 0,05 & 0,10 & 0,15 \\
\hline Rendimento $(\mathrm{g} / \mathrm{g})$ & 0,35 & 0,31 & 0,30 \\
Produtividade $(\mathrm{g} / \mathrm{L} / \mathrm{h})$ & 0,12 & 0,11 & 0,08 \\
Consumo de açúcar $(\%)$ & 56,2 & 46,3 & 33,9 \\
Tempo de fermentação (h) & 116 & 92 & 92 \\
\hline
\end{tabular}

Apesar do melaço utilizado apresentar em sua composição uma concentração elevada de carboidratos $(70,8 \mathrm{~g} / \mathrm{L})$, a conversão em ácido láctico não foi satisfatória. Esse melaço é procedente de lavouras que geralmente recebem aplicação de herbicidas e pesticidas, os quais podem aparecer na composição do mesmo, podendo prejudicar o processo fermentativo. Dimmling e Nesemann (1985 apud DROZD, 1987), relataram que melaço geralmente é impuro e contém herbicida, pesticida e resíduos químicos usados no processamento da cana-deaçúcar. Apesar de não acarretar danos toxicológicos para humanos e animais, podem causar problemas em algumas fermentações.

Valores de rendimento de ácido láctico como 0,76g/g foram descritos por Kwon, Kaul e Mattiasson (1996) utilizando meio semi-sintético contendo glicose como fonte de carbono e enriquecido com extrato de levedura e triptona. Ainda que os valores de rendimento de ácido láctico obtidos no atual trabalho sejam inferiores, a utilização de melaço de cana-deaçúcar suplementado constitui uma alternativa economicamente viável, se considerarmos o baixo custo quando comparado com o preço dos meios semisintéticos.

\section{Conclusão}

Melaço de cana-de-açúcar, previamente tratado com invertase e suplementado com extrato de levedura e peptona, mostrou ser um meio de cultivo economicamente viável para produção de ácido láctico. Nestas condições, a menor taxa de diluição foi mais adequada para o desenvolvimento da fermentação contínua do L.curvatus.

\section{Agradecimentos}

À CAPES e CPG-UEL pelo apoio financeiro.

\section{Referências}

AMRANE, A.; PRIGENT, Y. Influence of yeast extract concentration on batch cultures of Lactobacillus helveticus: growth and production coupling. World Journal of Microbiology and Biotechnology, Oxford, v.14, n. 4, p. 529-534, 1998.

BARCENA,J.M.; RAGOUT,A.L., CORDOBA,P.R.; SINERIZ, F. Continuous production of $\mathrm{L}(+)$-lactic acid by Lactobacillus casei in two-stage systems. Applied Microbiology and Biotechnology, Berlin, n.26, p.231-237, 1998.

BULUT, S.; ELIBOL, M.; OZER, D. Effect of different carbon sources on $\mathrm{L}(+)$ lactic acid production by Rhizopus oryzae. Biochemical engineering Journal, Amsterdam, v.21, n.1, p.33-37, 2004.

CHOUDHURY, B.; BASHA, A.; SWAMINATHAN, T. S. Study of lactic acid extration with higher molecular weight aliphatic amines. Journal of Chemical Technology and Biotechnology, London, v.72, p.111-116, 1998.

DEMIRCI, A.; POMETTO, A. L.; LEE, B.; HINZ, P. N. Media evaluation of lactic acid repeated-batch fermentation with Lactobacillus plantarum and Lactobacillus casei subsp. rhamnosus. Journal of Agricultural and Food Chemistry, Easton, v.46, n.11, p.4771-4774, Nov. 1998. 
DROZD, J. W. Hydrocarbons as feedstocks for biotechnology. In: STOWELL, J. D.; BEARDSMORE, A. J.; KEEVIL, C. W.; WOODWARD, J. R. Carbon substrates in biotechnology. Washington: IRL Press, 1987. Cap. 7, p. 119-138.

EVANGELISTA, R. L.; NIKOLOV, Z. L. Recovery and purification of lactic acid from fermentation broth by adsorption. Applied Biochemistry and Biotechnology, Berlin, v.57/58, p. 471-480, 1996.

COUTINHO FILHO, U.; HORI, C. E.; RIBEIRO, E. J. Influence of the reaction products in the inversion of sucrose by invertase. Brazilian Journal of Chemical Engineering, São Paulo, v.16, n.2, p.01-08, Jun. 1999.

GOMEZ, F. P. Estatística Experimental. 11. ed. Piracicaba: Nobel, 1985.

JAGNOW, G.; DAWID, W. Biotecnología: introducción con experimentos modelo. Zaragoza: Acribia, 1991.

KOTZAMANIDIS, C.; ROUKAS, T.; SKARACIS, G. Optimization of lactic acid production from beet molasses by Lactobacillus delbrueckii NCIMB 8130. World Journal of Microbiology \& Biotechnology, Oxford, v.18, n.5, p.441-448, 2002.

KWON, Y. J.; KAUL, R.; MATTIASSON, B. Extractive lactic acid fermentation in poly (ethyleneimine)-based aqueous two-phase system. Biotechnology and Bioengineering, New York, v.50, p.280-290, 1996.

MAN, J. C.; ROGOSA, M.; SHARPE, M. E. A medium for the cultivation of Lactobacilli. Journal of Applied Bacteriology, Oxford, v.23, p.130-135, 1960.

MARTÍNEZ-GONZÁLEZ, Y.; QUIROZ-CAMACHO, M. H.; LEDEZMA-PÉREZ, A. S.; JARAMILLO-CORONADO, J. C. Produccíon de ácido láctico a partir de melaza pretratada utilizando Lactobacillus delbrueckii. Revista Latino-Americana de Microbiologia, São Paulo, v.30, n.2, p.209-214, 1988.

MONTELONGO, J. L.; CHASSY, B. M.; McCORD, J. D. Lactobacillus salivarus for conversion of soy molasses into lactic acid. Journal of Food Science, Chicago, v. 58, n. 4, p. 863-866, 1993.

MORAES, I. O.; CAPALBO, D. M. F.; MORAES, R. O. Multiplicação de agentes de controle biológico. In: BETTIOL, W. Controle biológico de doenças de plantas. Brasília: EMBRAPA, 1991.p. 253-272.
NELSON, N. A photometric adaptation of the Somogyi method for determination of glucose. Biochemistry, New York, v.153, p.375-380, 1944.

OLIVEIRA, A. R.; BUZATO, J. B.; OLIVEIRA, A. S.; HAULY, M. C. O. Produção de ácido lático por Lactobacillus curvatus, em fermentação contínua, utilizando melaço de cana-de-açúcar previamente tratado com invertase. Revista Científica da UNOPAR, Londrina, v.2, n.2, p.1-7, 2000.

OLIVEIRA, A. S. Desenvolvimento de Inoculante para Fermentação Lática de Silagens: utilização de Resíduos Agroindustriais. Londrina, 1995. Tese (Doutorado em Ciências de Alimentos) - Departamento de Tecnologia de Alimentos e Medicamentos, Universidade Estadual de Londrina, Londrina.

PAYOT, T.; CHEMALY, Z.; FICK, M. Lactic acid production by Bacillus coagulans - Kinetic studies and optimization of culture medium for batch and continuous fermentations. Enzyme \& Microbial Technology, New York, v. 24, n. 3-4, p. 191-199, 1999.

ROYCHOUDHURY, P. R.; SRIVASTAVA, A.; SAHAI, V. Extractive Bioconversion of Lactic Acid. Advances in Biochemical Engineering and Biotechnology, Berlin, v.53, p.61-87, 1995.

SELMER-OLSEN, E.; SORHAUG, T. Comparative studies of the growth of Lactobacillus plantarum in whey supplemented with autolysate from brewery yeast biomass or commercial yeast extract. Milchwissenschaft Milk Science International, Munchen, v.53, n.7, p.367-370, 1998.

SILVA, D. J. Determinação do $\mathrm{pH}$, da acidez titulável e do ácido lático da silagem. In: SILVA, D. J. Análise de Alimentos (Métodos Químicos e Biológicos). Viçosa: Universidade Federal de Viçosa, 1981. Cap. 14, p.110-114.

SOMOGYI, M. A. A new reagent for determination of sugar. Journal Biology Chemistry, Cambridge, v.160, p.6168, 1945.

ZAYED, G.; WINTER, J. Batch and continuous production of lactic acid from salt whey using free and immobilized cultures of lactobacilli. Applied Microbiology and Biotechnology, Berlin, v.44, p.362-366, 1995.

ZHENG, Y.; DING, X.; CEN, P.; YANG, C. W.; TSAO, G. T. Lactic acid fermentation and adsorption on PVP. Applied Biochemistry and Biotechnology, Berlin, v. 57/58, p. 627633, 1996. 